\title{
Tidal migration patterns of juvenile penaeid shrimps in a French Guianese coastal mangrove
}

\author{
P. Dumas
}

IRD, UR ELISA, BP 165, 97323 Cayenne, French Guyana. E-mail : pascal.dumas@ird.fr

\begin{abstract}
In French Guyana, the dynamics of young prawn migrations from marine to estuarine waters remains equivocal, raising the question of habitat utilization in the adjacent mangrove systems. The temporal distribution of juvenile penaeid species was thus investigated in the main drainage channel of a Guianese coastal mangrove. A total of 2275 juvenile prawns belonging to five species, including two penaeid species (Penaeus subtilis, Xiphopenaeus kroyeri) were collected by stake net on four occasions during the wet season. Catches were dominated by large-sized, highly-valued $P$. subtilis and exclusively occurred (a) at the end of flood tide and (b) at the beginning of ebb tide, when water velocity was maximum. Size structures were very similar between flood- and ebb tides, suggesting that the same assemblages entered then withdrawed from the mangrove on a given tidal cycle. Residence times of prawns in the mangrove were short (3-4 hours per tidal cycle), as juveniles gained access to the coastal mangrove only a few hours per day during high tide. These results will need further confirmation at larger (Guianese) scale, but provide evidence for original, tidal-dominated mangrove utilization patterns by juvenile prawns. Given the economic importance of P. subtilis in French Guyana, there is an urgent need to assess the contribution of coastal mangrove habitats to sustaining near shore fisheries.
\end{abstract}

Keywords : penaeid prawns, mangrove, tidal migrations, French Guyana.

\section{Introduction}

Mangroves are distributed throughout the world in the equatorial and subtropical regions, where they often dominate in estuarine and coastal zones (Tomlinson 1986, Twilley et al. 1996). They are generally recognized as complex, productive ecosystems that support diverse ecological assemblages (Odum \& Head 1975, Robertson \& Duke 1987, Sasekumar et al. 1992, Lee 1999) and provide a variety of goods and services (Ewel et al. 1998). Many studies have demonstrated their importance as shelter from predation, feeding or nursery places for a variety of fish and invertebrate species (e.g. Sasekumar et al. 1992, Primavera 1998, Vance et al. 1990, 2002, Rönnback et al. 2002). In particular, juvenile shrimps (e.g. penaeid prawns) are important components of the invertebrate fauna as postlarvae usually move from marine to coastal or estuarine backwaters during their lifecycle (Garcia \& Le Reste 1981, Staples \& Vance 1985). Yet, the question of mangrove utilization by juvenile prawns still remains controversial due to the high diversity observed among mangrove habitats (Chong et al. 1990, Hoss \& Thayer 1993). Extensive studies conducted in the estuaries of French Guyana by Vendeville \& Lhomme (1997) emphasized original trends: in opposition with the classical view (young prawns usually settling in estuarine waters for months to grow out), juveniles prawns exhibited highly-periodic, very short residence time in estuaries under the influence of tidal cycles. The consequences of similar temporal patterns remains equivocal for the adjacent mangrove systems, raising the question of habitat utilization patterns.

The aim of this study was to investigate the migrations patterns of juvenile prawns in a Guianese coastal mangrove, to answer the following questions: (1) What are the temporal patterns of mangrove utilization by penaeid shrimps? and (2) What are the local environmental factors that influence shrimp migrations in and out of the mangroves?

\section{Material and Methods}

\section{Study area}

The study was performed in the estuary of Macouria Creek, a short mangrove-lined river $30 \mathrm{~km}$ west of Cayenne (French Guyana - Fig. 1). The area is located in the wet tropics (average rainfall $2900 \mathrm{~mm}^{\text {year-1 }}{ }^{-1}$, Betoulle et al. 2001). The climate is characterized by the alternation of wet (December-July) and dry 


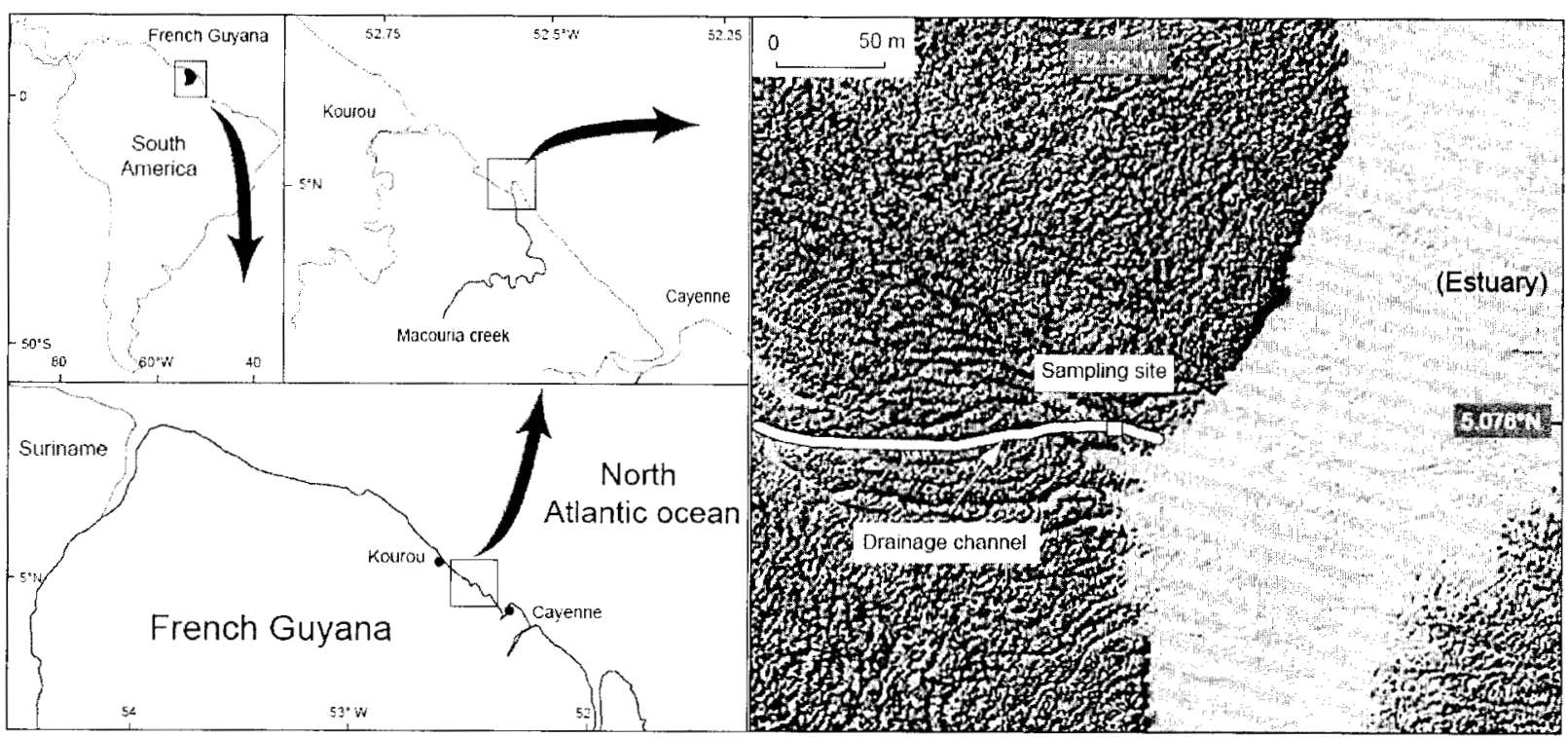

Fig. 1. Location of the sampling site in the drainage channel of the coastal mangrove, Macouria Creek, French Guyana. LIDAR imagery of the studied zone, () V. Gond (ALTOA-CIRAD-IRD).

(August - November) seasons. In French Guyana, mangroves form a quasi-continuous band along the $350 \mathrm{~km}$ shoreline (Travassos 1994). Ranging from a few meters to more than $15 \mathrm{~km}$ width, they are under the dependence of unstable coastline dynamics due to very fast successions of erosion or colonization phases related to the Amazon sediment dispersal system (Betoulle et al. 2001).

Only four mangrove species are found in Guianese mangrove forests (Fabre et al. 1999). The study was conducted in a sea edge pioneer mangrove dominated by young (1-4 years old) Avicennia germinans (L.), located in front of extensive mud banks that are characteristics of the Guianese shoreline. The sampling site was located in the main drainage channel of the man- grove forest, a small (10 m-wide) creek, $400 \mathrm{~m}$ upstream from the mouth of Macouria Creek. This channel is completely drained of waters during low spring tides, with a maximum tidal range of about two meters. The substratum in both the channel and the adjacent parts of the mangrove is fine mud.

\section{Sampling procedures}

Juvenile shrimps were collected using a $10 \mathrm{~m}$ x $2 \mathrm{~m}$ rectangular, $5 \mathrm{~mm}$ mesh-sized stake net, tied across the channel and fixed to the bottom of the sediment using a lead line. As a major confounding factor in the study of prawn distribution is the influence of tidal inundation (Meager et al. 2003), similar sampling periods were chosen on the basis of their tidal characteristics

Table 1. Sampling and environmental characteristics in the mangrove drainage channel, Macouria creek, French Guyana. $\mathrm{H}$ : number of hauls per sampled date.

\begin{tabular}{|clccccc|}
\hline Date & Sample period & $\mathrm{H}$ & $\begin{array}{c}\text { High tide } \\
\text { level }(\mathrm{m})\end{array}$ & $\begin{array}{c}\text { Tidal } \\
\text { range }(\mathrm{m})\end{array}$ & $\begin{array}{c}\text { Temperature } \\
\min -\max \left({ }^{\circ} \mathrm{C}\right)\end{array}$ & $\begin{array}{c}\text { Salinity } \\
\min -\max (\%)\end{array}$ \\
\hline $05 / 05 / 04$ & Flood tide & 5 & 3.25 & 2.20 & $26.5-29.8$ & $0.0-20.0$ \\
$17 / 05 / 04$ & Flood tide & 5 & 3.00 & 1.65 & $29.2-33.6$ & $0.0-26.87$ \\
$01 / 06 / 04$ & Flood + ebb tide & 13 & 3.10 & 1.90 & $27.5-30.4$ & $0.31-24.74$ \\
$08 / 06 / 04$ & Ebb tide & 6 & 3.05 & 1.85 & $26.3-28.5$ & $2.5-24.4$ \\
& & & & & & \\
\hline
\end{tabular}


(low/high tide levels, tidal range, Table 1). After preliminary tests, samples were taken during the wet period when water levels were maximum and the study site more easily accessible. Shrimps were collected on four dates between May and June 2005, in general during a half tidal cycle (flood or ebb tide) except on one occasion when sampling was possible during the whole tidal cycle (see Table 1). Every 30 minutes, the net was raised and the juvenile shrimps were hand-collected. Once all individuals were collected, the net was immediately lowered in the channel and the specimens were preserved in $70 \%$ ethanol. In the laboratory, all specimens were identified to species level and counted. Penaeid shrimps (Penaeus subtilis, Xiphopenaeus kroye$r i$ ) were measured for cephalothoracic length (LC hereafter) and grouped into size classes.

The following environmental parameters were measured to follow the intrusion of dense, marine waters : temperature, salinity (recorded using WTW portable meters) and current velocity (measured with a General Oceanics mechanical flowmeter). After preliminary tests, the probes and flowmeter were located $10 \mathrm{~cm}$ above the bottom in the centre of the channel, just in front of the net. Due to field conditions and technical constraints, sampling frequencies differed over the study for the considered parameters (1-15 minutes intervals). Measurements began 15 minutes before the net installation and ended 15 minutes after the last catch. In order to obtain a representative view of the channel functioning over a complete tidal cycle, water level and velocity were continuously recorded over $24 \mathrm{~h}$ on a single occasion using a digital SIGMA flowmeter equipped with a submerged depth and velocity sensor.

\section{Statistical analyses}

Temporal variations in shrimp catches were investigated using non-parametric one-way analyses of variance (Kruskall-Wallis ANOVA, Zar 1984). Catch rates (numbers of individuals collected. $\mathrm{h}^{-1}$ ) and measured individuals length were compared between the four sampling dates for penaeid species (P. subtilis, $X$. kroyeri). In the same way, intra-tidal variations in juvenile size were assessed for each sampling date using Kruskall-Wallis ANOVA on LC data from samples collected at 30 minutes intervals. Size-class distribution patterns were compared between flood and ebb tides using the Kolmogorov-Smirnov test.

\section{Results}

\section{Environmental parameters}

The monitoring of environmental parameters in the drainage channel highlighted the influence of tidal events. The range of salinity variation in the channel during a tide was 20 to $26.9 \%$ (Table 1). This range characterized changes from fresh- to brackish waters during the tidal cycles, average salinity values shifting from 0.7 to $24.0 \%$ about 2 hours before high tide, highlighting the intrusion of marine waters in the channel during flood. Salinity then declined progressively and returned to base levels about two hours after high tide. Average water temperature in the channel ranged from 26.8 to $31.7^{\circ} \mathrm{C}$; tidal variation over the sampling periods ranged from 2.2 to $4.4{ }^{\circ} \mathrm{C}$ (Table 1). A shift in

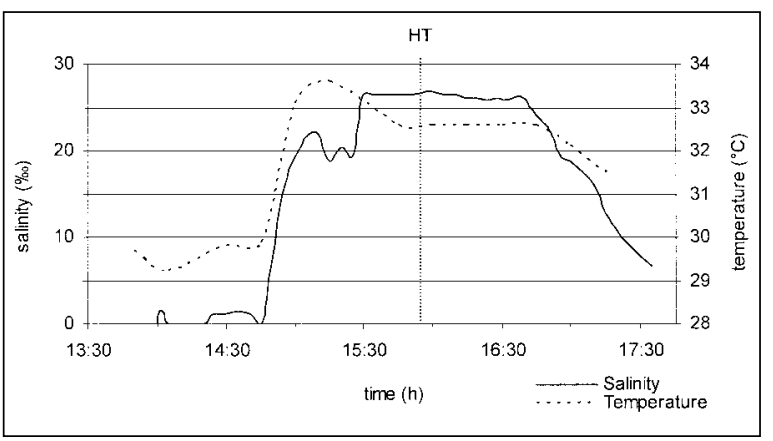

Fig. 2. Variations of water characteristics related to marine inflow in the drainage channel, Macouria Creek, French Guyana (17/05/04). HT = high tide.

temperature associated to the warm, marine waters entering the channel was generally observed during the flood (Fig. 2) ; temperature declined thereafter during the ebb tide.

For the hydrological parameters, a progressive increase of current speed and water levels was observed during flood tide, i.e. waters entering the mangrove system through the channel. The maximum current velocity was reached shortly after the salinity shift, before high tide. Inversion of flow occurred at high tide

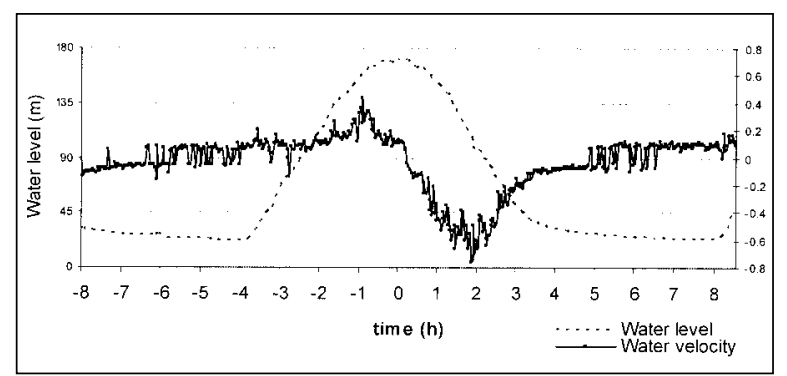

Fig. 3. Tidal variations of hydrological parameters in the mangrove drainage channel, Macouria Creek, French Guyana. Water level and current velocity monitoring ( 2 minutes intervals) over a complete tidal cycle. $(0<->$ high tide). For water velocities, positive values refer to flood tides, negative values to ebb tides. 
when water level was at a maximum, then the channel drained off (Fig. 3). Dissimilarity was observed between flood and tide, the maximum current velocity always being observed during the draining event.

\section{Species composition and abundance}

About 2300 individuals from four main species were collected in the drainage channel over the sampling dates: Penaeus subtilis Perez Farfante, 1967 (48.97 \% of total abundance), Xiphopenaeus kroyeri (Heller, 1862 - $37.05 \%$ ), Macrobrachium amazonicum (Heller, $1862-5.05 \%)$ and Nematopalaemon schmitti (Holthuis, 1950 - $4.92 \%$ ). Macrobrachium carcinus (Linné, 1758) were also collected but were very rare $(<10$ indiv.). Penaeid shrimp species (P. subtilis, X. kroyeri) dominated numerically the catches $(\sim 86 \%$ of total abundance). The catch rate ranged from 0 to 932 individuals. $\mathrm{h}^{-1}$ and exhibited a strong intra-tidal variability,

Table 2. Variations of the penaeid prawns catches in the mangrove drainage channel, Macouria creek, French Guyana. Catch rates (ind.h-1), juvenile sizes (mm); mean + SD for the sampling dates. Between-date Kruskall-Wallis ANOVAs (H coefficient and probability).

\begin{tabular}{|c|c|c|c|c|c|c|}
\hline & \multicolumn{4}{|c|}{ Date } & \multirow[b]{2}{*}{$\mathrm{H}$} & \multirow[b]{2}{*}{$p$} \\
\hline & $05 / 05 / 04$ & $17 / 05 / 04$ & $01 / 06 / 04$ & $08 / 06 / 04$ & & \\
\hline \multicolumn{7}{|l|}{ Cath rate } \\
\hline P. subtilis & $158(230)$ & $101(123.8)$ & $58.6(149)$ & $71.6(64)$ & 4.91 & 0.18 N.S \\
\hline$X$. kroyeri & $90(180)$ & $140(280)$ & $59(187)$ & 0 & 2.72 & 0.44 N.S \\
\hline \multicolumn{7}{|l|}{ Length LC } \\
\hline P. subtilis & $10.2(1.5)$ & $9.0(1.2)$ & $9.2(1.7)$ & $9.8(1.6)$ & 116.2 & $<0.0001$ \\
\hline$X$ kroyeri & $10.6(2.5)$ & $8.5(1.7)$ & $9.6(2)$ & - & 115.23 & $<0.0001$ \\
\hline
\end{tabular}

as the catches were not equally distributed over the tidal cycles whatever the considered species. Betweendate variations were not significant (Kruskall-Wallis ANOVA, cf Table 2) and were not related to environmental parameters.

The temporal distribution of catches over the tidal cycles showed a marked, bimodal distribution. The catch rates were maximum about 1 hour before and 23 hours after high tide for the considered sampling dates, corresponding to discrete events observed in the channel: a) juveniles suddenly entering the mangrove with flood tide ; b) juveniles flowing out with the ebb tide. The prawn peaks occurred when current velocities were maximum in the channel, around one hour after the main salinity variations: a) marine shift, b) return to base levels. This pattern was consistent between the sampling dates and was observed whatever the species considered (Fig. 4).

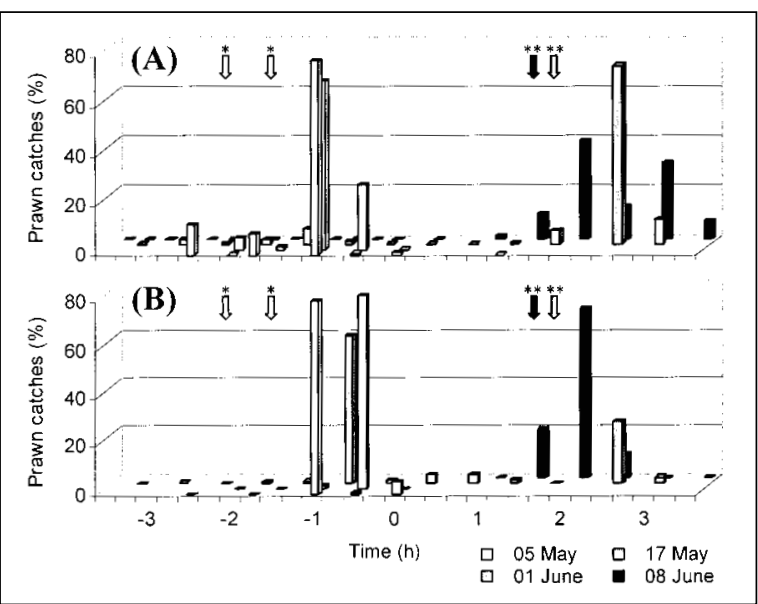

Fig. 4. Variations of prawn catches during the 4 sampling dates in the drainage channel, Macouria Creek, French Guyana. Relative abundance of individuals collected per date for (A) $P$. subtilis and (B) cumulated other species for the 4 sampling dates. $(0<->$ high tide). Arrows : salinity events (* marine shift, $* *$ return to base levels).

\section{Size composition}

Few juveniles were caught that were smaller than $6 \mathrm{~mm} \mathrm{LC}$, regardless of the sampling date or species in question. All the individuals collected were juveniles. For penaeid species, LC ranged from 5.7 to $16.7 \mathrm{~mm}$

and from 5.3 to $19.1 \mathrm{~mm}$ for $P$. subtilis and X. kroyeri, respectively. Significant differences were observed between the sampling dates for both species (P. subti-

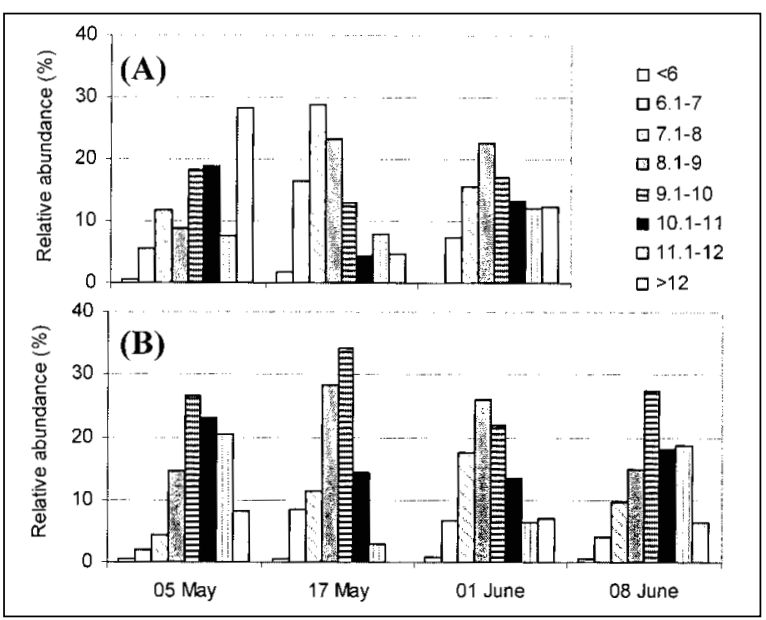

Fig. 5. Length-frequency distribution of penaeid prawns in the drainage channel, Macouria creek, French Guyana. Relative abundances for the $8 \mathrm{LC}$ size-classes for (A) X. kroyeri and (B) P. subtilis between the sampling dates. 
lis / X. kroyeri : average LC from 9.0 to 10.2 / from 8.5 to $10.6, \mathrm{p}<0.0001$, Kruskall-Wallis ANOVA, cf Table 2). Dominant size classes were $8-11 \mathrm{~mm}$ and $7-10 \mathrm{~mm}$ for $P$. subtilis and X. kroyeri, respectively $(64.8 \% /$ $55.1 \%$ of total catches - Fig. 5).

No significant intra-tidal variations were observed for juveniles body lenghts: measured LC did not differ during sampling whatever the considered periods (Kruskall-Wallis ANOVA for the four sampling dates, $\mathrm{H}$ from 2.3 to 7.3 , p from 0.08 to 0.32 , N.S.). In the same way, size-class distribution patterns did not exhibit significant differences between flood and ebb tides for

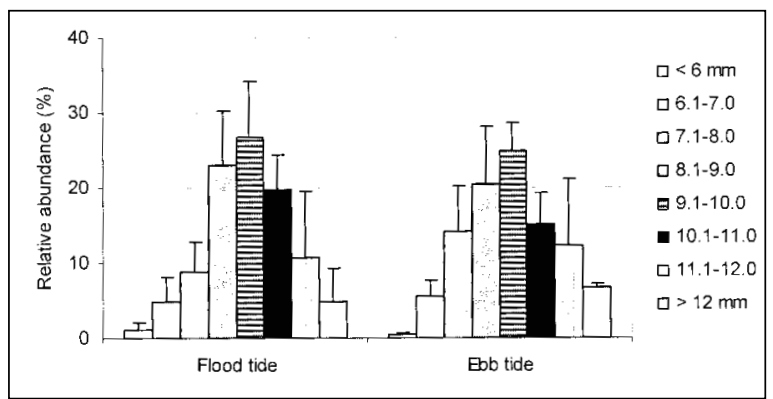

Fig. 6. Size-class distribution patterns between flood and ebb tide in the drainage channel, Macouria creek, French Guyana. Relative abundances for the 8 LC size-classes between flood and ebb tides for $P$. subtilis.

the considered dates (Kolmogorov-Smirnov test for both $P$. subtilis and X. kroyeri, $\mathrm{p}>0.99$, N.S.): populations entering the mangrove system had a remarkably similar size structure compared to those flowing out (Fig. 6).

\section{Discussion}

One of the reasons frequently used to support the conservation and management of mangroves is their ecological importance for fish and shrimp species (Sheridan \& Hays 2003). While quantitative relationships between mangroves extent and fisheries productivity are still controversial (Lee 2004), the extensive use of mangrove as habitats for juvenile nekton is currently widely recognized, whatever the species or geographical zones considered (Rönnback et al. 2002). Juvenile shrimps, in particular the commercial penaeid species (e.g. the large-sized genera Penaeus), are thus reported from a large variety of mangrove habitats including estuaries, creeks, inlets, intertidal forests, mud and sand flats (De Freitas 1986, Chong et al. 1990, Primavera 1997, Rönnback et al. 1999, 2002, Meager et al. 2003).

\section{Species catches}

Five species of juvenile shrimps including two penaeid species were collected in the main drainage channel of a sea-edge mangrove system. Among the penaeid species, Penaeus subtilis is a large-sized, highly valued species which represents a major commercial resource for French Guyana (average capture production $~ 4000$ t.year $^{-1}$, Vendeville pers. comm.). Despite their potential abundance in commercial captures, Xiphopenaeus kroyeri as well as Nematopalaemon schmitti are not currently exploited, mainly due to low commercial values. The two Macrobrachium species are mainly freshwater shrimps, moving to estuaries and brackish waters for spawning. All these species are known from Guianese estuaries (Vendeville \& Lhomme 1997) and were caught whatever the sampling dates, except for $X$. kroyeri on a single occasion $(08 / 06 / 04)$ and the very rare $M$. carcinus, collected in very low abundance (< 10 indiv.).

\section{Juveniles flow patterns}

While distribution data of juvenile prawns in mangrove systems are generally investigated on larger temporal scales (usually seasonal e.g. Robertson \& Duke 1987, Mohan et el. 1995, Sasekumar et al. 1992, Meager et al. 2003, among others), in this study we focused on short temporal, intra-tidal variations of penaeid catches. The results emphasized the importance of tidal cycles in the prawn migrations: peaks of juveniles were punctually observed in the channel, i.e. around one hour before to two hours after high tide for the considered hydroperiod. Except for these punctual events, almost no juveniles were collected over the whole tidal cycle. The same behaviour was observed whatever the shrimp species considered, in particular the dominant penaeid species Penaeus subtilis and Xiphopenaeus kroyeri, and did not exhibit variations between the sampling dates despite the high variability in juveniles abundances (total catches per date from 225 to 1019 individuals). This pattern could be clearly related to the hydrological changes occurring during the tidal cycle. Catches occurred when water velocity reached its maximum in the channel (a) at the end of flood tide with the sudden inflow from marine waters and (b) at the beginning of ebb tide with the rapid draining of the mangrove system through the channel.

We are aware that these results should be carefully considered, in the context of the restricted study period (four dates during the wet season). Prawn dynamics may in particular vary during the year between hydrological (wet/dry) periods or tidal phases, in response to environmental factors. Low-water level periods (e.g. 
during neap tides) in particular did not allow channel immersion, as observed during the preliminary tests. Yet, similar trends were observed in non-mangrove, Guianese coastal habitats by Vendeville $(1993,1994)$ and Vendeville \& Lhomme (1997: periodic, tidal-dominated movements of $P$. subtilis postlarvae were thus reported between estuarine and near shore marine waters in 13 estuaries over a five-years study period. This phenomenon was described as «shrimp postlarvae intrusion into estuaries ».

We also observed very similar size patterns for the prawn catches between flood and ebb tides, as reported by these authors. Although inferring population dynamics from this limited data set may be hazardous, they suggest that the same prawn assemblages may enter then withdraw from the mangroves on a given tidal cycle. This proposition will still require further sampling effort to be tested : in this first study, technical constraints (in particular harsh environmental conditions and difficult access to the drainage channel) did not allow continuous sampling of the juveniles over a complete tidal cycle, except on a single occasion. Yet, in this latter case the total catches between ebb and flood were of the same order of magnitude (450 / 569 individuals) and exhibited similar size structure, at least for the most abundant $P$. subtilis.

\section{Mangrove utilization by juvenile prawns}

Fish and prawns generally occur in greater abundance in mangroves than in adjacent near shore habitats (Sasekumar et al. 1992), but variations in the patterns of mangrove utilization have often been reported by authors. In Malaysia, Chong et al. (1990) reported evidence for tidal migrations of juvenile fishes and prawns, moving into estuaries to feeding grounds from adjacent mud flats/mangrove swamps. In the Philippines, Primavera (1998) suggested a strong, yearround nursery role for a riverine mangrove, while adjacent island mangroves exhibited a limited nursery use. More recently, Rönnback et al. (2002) demonstrated the extensive use of contrasted mangrove microhabitats in a Mozambique island.

In French Guyana, Vendeville \& Lhomme (1997) challenged the paradigm of inshore waters as critical nursery sites where young penaeid prawns settle for months, providing evidence for a very discontinuous utilization of estuarine habitats. Our results support this proposition. In the coastal mangrove system studied, the mangrove forest and associated waterways are entirely drained of waters during the majority of the tidal cycle. Juveniles thus gained access to the coastal mangrove only a few hours per day during high tide, when large sections of the mangrove system become available, including smaller channel network and mangrove forest. The maximum residence time of prawns in the mangrove system could thus be evaluated to three to four hours per tidal cycle, as sampling conditions were chosen so as to provide patterns representative of optimal conditions (high tide levels close to the upper local values, allowing maximum tidal inundation). Preliminary tests in the adjacent mangrove forest confirmed the presence of juvenile shrimps during high tides, but with low densities (Dumas, unpubl. dat.). These observations appear consistent with recent studies on the spatial distribution of juvenile penaeids that reported decreasing catches with increasing distance from the channel edge into the mangrove (Vance et al. 2002, Meager et al. 2003).

In the context of this preliminary study, assessing the importance of the Guianese mangroves for the penaeid species would be premature due to the limited spatio-temporal coverage of the data. Moreover, the pervasive concept of "nursery" has been rarely stated clearly and remains equivocal (Sheridan \& Hays 2003). Whether the definition may rest upon structural (e.g. juvenile densities, sizes, residence times) or functional criteria (e.g. growth, survival, shelter effects), the nursery status of the mangrove may differ. Yet, for the considered Guianese mangrove, the trends observed towards periodic, highly-discontinuous habitat utilization may not argue in favour of an "exclusive nursery" status.

\section{Conclusion}

With the world-wide decline of mangrove forests due to human activities, the question of mangrove utilization is of particular importance from a conservation perspective, as the economic significance of the coastal mangroves may dramatically differ whether they are considered as nurseries for commercially important species or not. In the framework of the "shrimps postlarvae intrusion into estuaries" concept they developed in the early 90', Vendeville \& Lhomme (1997) thus hypothesized the existence of a unique, continuous near shore nursery along the Guianese shoreline. While this hypothesis still has to be formally tested and bearing in mind their scale restrictions, our results provided original evidence for cyclic, tidal-dominated utilization of the Guianese coastal mangrove by juvenile prawns, in particular commercial penaeid species, that may use mangrove at least as feeding grounds. At this point, there is an obvious need for complementary data on juvenile prawn distribution in the adjacent habitats, as well as large-scale spatio- 
temporal testing of these results in different Guianese coastal systems. Further studies should in particular encompass hydrodynamical modelling of coastal mangroves, as diffuse juveniles flows also occur through small channel networks or with marine waters overflow. The high values of current speed monitored also raised the question of active vs. passive habitat selection by the juvenile prawns, with spatio-temporal distributions that may be the result of passive transports by tidal currents and/or active habitat choice at high tide.

Once they emigrate from coastal habitats (whatever they are), $P$. subtilis prawns integrate adult, offshore stocks targeted by commercial fisheries. Given the direct economic importance of $P$. subtilis in French Guyana, there is an urgent need in assessing the contribution of coastal mangrove habitats to sustaining near shore fisheries.

\section{Acknowledgement}

Thanks are due to A. Belhandouze, M. Tarcy and R. Franquet for field assistance. We are also grateful to P. Vendeville for useful discussions and to the two anonymous reviewers for constructive comments and suggestions.

\section{References}

Betoulle J.-L., Fromard F., Fabre A. \& Puig H. 2001. - Caractérisation des chutes de litière et des apports au sol en nutriments dans une mangrove de Guyane française. Can. J. Bot., 79, 238-249.

Chong V.C., Sasekumar A., Leh M.U. \& D'Cruz R. 1990. - The fish hand prawn communities of a Malaysian coastal mangrove system, with comparisons to adjacent mud flats and inshore waters. Estuar. Coast. Shelf Sci., 31, 703-722.

De Fretias, A.J. 1986 - Selection of nursery areas by six southest African Penaeidae. Estuar. Coast. Shelf Sci., 23, 901-908.

Ewel K.C., Twilley R. R. \& Eon gong J. 1998. - Different kinds of mangrove forests provide different goods and services. Global Ecology and Biogeography letters, 7, 83-94.

Fabre A., Fromard F. \& Trichon V. 1999. - Fractionation of phosphate in sediments of four representative mangrove stages (French Guiana). Hydrobiologia, 392, 13-19.

Garcia S. \& Le Reste L. 1981. - Cycles vitaux, dynamique, exploitation et aménagement des stocks de crevettes pénéides côtières. FAO, Doc. Tech. Pêches, 203, 210 p.

Hoss D.E. \& Thayer G.W. 1993. - The importance of habitat to the early life history of estuarine dependant fishes. Am. Fish. Soc. Sympos., 14, 147-158.

Odum W.E. \& Head E.J. 1975. - The detritus-based food web of an estuarine mangrove community. Bull. Mar. Sci., 22, 671-738.

Lee S.Y. 1999. - Tropical mangrove ecology : physical and biotic factors influencing ecosystem structure and function. Austr. $J$. Ecol., 24, 355-366.

Lee, S.Y. 2004. - Relationship between mangrove abundance and tropical prawn production : a re-evaluation. Mar. Biol., 145, 943949.

Meager J.J., Vance D.J., Williamson I. \& Loneragan N.P. 2003 - Microhabitat distribution of juvenile Penaeus merguiensis de Man and other epibenthic crustaceans within a mangrove forest in subtropical Australia. J. Exper. Mar. Biol. Ecol., 294, 127-144.

Mohan R., Selvam V. \& Azariah J. 1995. - Temporal distribution and abundance of schrimp postlarvae and juveniles in the mangrove of Muthupet, Tamilnadu, India. Hydrobiologia, 295, 183-191.

Primavera J.H. 1997 - Fish predation on mangrove-associated penaeids. The role of structure and substrate. J. Exp. Mar. Biol. Ecol., 215, 205-216.

Primavera J.H. 1998. - Mangroves as nurseries: shrimp populations in mangrove and non-mangrove habitats. Estuar. Coast. Shelf. Sci., 46, 457-467.

Robertson A.I. \& Duke N.C. 1987. - Mangrove as nursery sites : comparisons of the abundance and species composition of fish and crustaceans in mangroves and other nearshore habitats in tropical Australia. Mar. Biol., 96, 193-205.

Rönnback P., Macia A., Almqvist G., Schultz L. \& Troell M. 2002. - Do penaeid shrimps have a preference for mangrove habitats ? Distribution pattern analysis on Inhaca island, Mozambique. Estuar. Coast. Shelf Sci., 55, 427-436.

Rönnback P., Troell M., Kautsky N. \& Primavera J.H. 1999. - Distribution patterns of shrimps anf fish among Avicennia and Rhizophora microhabitats in the Pagbilao mangroves, Philippines. Estuar. Coast. Shelf Sci., 48, 223-234.

Sasekumar A., Chong V.C., Leh M.U. \& D'Cruz R. 1992. - Mangroves as habitat for fish and prawns. Hydrobiologia, 247, 195-207.

Sheridan P. \& Hays C. 2003. - Are mangroves nursery habitat for transient fishes and decapods ? - Wetlands, 23, 449-458.

Staples D.J. \& Vance D.J. 1985. - Short-term and long-term influences on the immigration of postlarval banana prawns Penaeus merguiensis into a mangrove estuary of the Gulf of Carpentaria, Australia. Mar. Ecol. Prog. Ser., 23, 15-29.

Tomlinson P.B. 1986. - The botany of mangroves. Cambridge University Press, Cambridge.

Travassos P. 1994. - Cartographie par télédétection optique et radar du littoral de la Guyane française. Importance de la mangrove pour la production crevettière. GDTA, Mémoire de D.E.S.S. GDTA-ENSG, 62p, ORSTOM - Cayenne.

Twilley R.R., Snedaker S.C., Yanez-Arancibia A. \& Medina E. 1996. - Biodiversity and ecosystem processes in tropical estuaries: perspectives of mangrove ecosystems. P327-370. In: H.A. Mooney, J.H. Cushmam, E.O Medina, O.E. Sala \& E.D. Schulze (eds.) Functional roles of biodiversity: a global perspective. John Wiley \& Sons Ltd., New-York.

Vance D.J., Haywood M.D. \& Staples D.J. 1990. - Use of a mangrove estuary as a nursery area by postlarval and juvenile banana prawns, Penaeus merguiensis de Man, in northern Australia. Estuar. Coast. Shelf Sci., 31, 689-702.

Vance D.J., Haywood M.D., Heales D.S., Kenyon R.A., Loneragan N.R., Pendrey R.C. 2002. - Distribution of juvenile penaeid prawns in mangrove forests in a tropical Australian estuary, with particular reference to Penaeus merguiensis. Mar. Ecol. Prog. Ser. 228, 165-177.

Vendeville P. 1993. - Des nurseries estuariennes de Penaeus subtilis en Guyane : mythe ou réalité ? Quelques réflexions à partir des données recueillies sur les estuaires d'avril 1988 à juin 1992. Rapport ORSTOM, 56 p, ORSTOM - Cayenne

Vendeville P. 1994. - La question des nurseries de crevettes en Guyane. Du concept d'intrusion estuarienne de postlarves à l'hypothèse de nurserie littorale. Rapport ORSTOM, 14p, ORSTOM Cayenne.

Vendeville P. \& Lhomme F. 1997. - Le cycle vital et le recrutement de la crevette Penaeus subtilis en Guyane. Rapport ORSTOM, 281 p, ORSTOM - Cayenne.

Zar J.H. 1984. - Biostatistical Analysis. Prentice-Hall, New-Jersey. 